\title{
In Vitro Radiographic Detection of Cement Overhangs on Cement-Retained Implant Restorations
}

\author{
Djordje Antonijevic, DDS, $\mathrm{PhD}^{1} /$ Kosovka Obradovic-Djuricic, DDS, $\mathrm{PhD}^{2}$ / \\ Zoran Rakocevic, $\mathrm{MD}, \mathrm{PhD}^{3} /$ Ivana Medigovic, $\mathrm{MSc}^{4}$
}

\begin{abstract}
Purpose: The aim of this in vitro study was to investigate the potential of digital and conventional radiography to detect small amounts of residual dental luting cements around implant abutments. Materials and Methods: Artificial cement and aluminum overhangs in varying thicknesses, heights, and depths were radiographed adjacent to implant restorations with a radiovisiography sensor. Five trained evaluators were asked to identify the smallest depth of overhang that could be detected on radiographs. Results: For detection of cement overhangs adjacent to implant abutments, a luting agent must have greater radiopacity than what is recommended by relevant International Organization for Standardization directives. To detect a 0.1-mm-thick portion of excess cement adjacent to an implant abutment, the cement should have a radiopacity of at least $1.7 \mathrm{~mm}$ of aluminum for high-resolution digital radiographs and $2.2 \mathrm{~mm}$ of aluminum for film-based radiographs. Two-way analysis of variance revealed that the thickness of the specimens, type of imaging detector, and type of cement all affected the radiopacity threshold for artificial cement excess $(\mathrm{P}<.05)$. The height of the specimens and the surrounding structures were not statistically significant factors in cement detection. Conclusions: Digital radiography offers better possibilities for visualization of cement excess than conventional radiography. INT J ORAL MAXILLOFAC IMPLANTS 2013;28:1068-1075. doi: 10.11607/jomi.3057
\end{abstract}

Key words: cement overhang, digital radiography, luting cement, radiopacity

mplant-supported fixed partial dentures and single crowns are generally classified as either cemented or screw-retained. ${ }^{1}$ Screw-retained prostheses have the advantage of retrievability, which allows replacement of prosthodontic components and peri-implant probing. In addition, screw-retained restorations provide better retention in areas of limited interarch space, result in smaller marginal gaps, and show less sulcus bleeding and plaque accumulation. ${ }^{2,3}$ A 3-year prospective study of peri-implant soft tissue health found that cement-retained crowns showed a worsening trend with respect to plaque accumulation and

\footnotetext{
${ }^{1}$ Affiliate Lecturer, Faculty of Medical Sciences, Clinic for Dentistry, University of Kragujevac, Kragujevac, Serbia.

${ }^{2}$ Professor, Faculty of Dentistry, Department of Prosthodontics, University of Belgrade, Belgrade, Serbia.

${ }^{3}$ Professor, Faculty of Dentistry, Department of Radiology, University of Belgrade, Belgrade, Serbia.

${ }^{4} \mathrm{PhD}$ Candidate, Institute for Biological Research Sinişa Stankovic, Department of Cytology, University of Belgrade, Belgrade, Serbia.
}

Correspondence to: Dr Djordje Antonijevic, Faculty of Medical Sciences, Clinic for Dentistry, University of Kragujevac, Svetozara Markovica br. 69, Kragujevac, Serbia. Email: djordjeantonijevic@medf.kg.ac.rs bleeding scores, while screw-retained prostheses presented the opposite picture. ${ }^{4}$ On the other hand, the drawbacks of screw-retained prostheses include abutment loosening and nonpassive fit of superstructures. In addition, the presence of screw holes on the occlusal surfaces can lead to poor esthetics, fracture of the porcelain around screw holes, disrupted occlusion, and inadequate anatomy of the canines, which may compromise anterior guidance and the restoration's ability to generate axial loading. ${ }^{1,5}$

Cement retention has become the standard of care in implant prostheses since retrievability has become less important as survival rates for dental implants have dramatically increased over the last few years. ${ }^{6}$ However, this restorative option also has some limitations, including irretrievability and larger marginal gaps. ${ }^{3}$ A substantial disadvantage of cement-retained restorations is the difficulty of completely removing excess cement from the implant surfaces; this has been associated with higher plaque accumulation and more frequent peri-implant disease. ${ }^{7,8}$

Peri-implant disease can be classified as peri-implant mucositis or peri-implantitis. ${ }^{9}$ Peri-implant mucositis presents with inflammatory lesions of the soft tissues surrounding implants, while peri-implantitis is associated with bone loss in addition to the soft tissue lesions. ${ }^{10}$ Peri-implantitis is a biologic complication 
that may lead to a failed implant. ${ }^{11}$ In cemented implant prostheses, peri-implantitis can arise when the rough surface of the residual cement retains microbes and inhibits the removal of microorganisms., ${ }^{8,12}$ Agar et $\mathrm{al}^{13}$ demonstrated that it is impossible to clean all cement remnants in deep subgingival cement placements because their direct visual identification is difficult. Hence, in most cases of peri-implantitis caused by cement overhangs, surgical procedures are necessitated for cement removal, which is not a sensible approach. ${ }^{14}$ Two techniques are described for noninvasive visualization of residual cement in submucosal implant shoulder locations: the use of a dental endoscope and radiographic examination..$^{8,15}$ While the use of endoscopy is not widespread among dental practitioners, radiography is performed routinely in clinical practice. If the small amounts of excess cement could be identified on the radiographic images and subsequently cleaned away, invasive open debridement for direct observation could be avoided.

The aims of this study were twofold: (1) to investigate whether the type of radiographic image (film or digital) affects the ability to visualize cement excess around implant restorations and (2) to evaluate the minimum (threshold) radiopacity value that dental cement of various thicknesses and heights should possess to be detected by radiographic means on implant restorations.

\section{MATERIALS AND METHODS}

Five specimens of each cement material tested (Table 1), $1 \mathrm{~mm}$ thick and $8 \mathrm{~mm}$ in diameter, were created so that the radiopacity of each could be determined in accordance with the International Standards Organization (ISO) guidelines. Specimens were radiographed adjacent to an aluminum (Al) stepwedge in 1-mm incremental steps with a radiovisiography sensor (RVG-4, Trophy Radiology). The Al stepwedge was used to calibrate the radiographs, with three exposures for each of 10 steps. An x-ray unit operating at $70 \mathrm{kVp}$ and $7 \mathrm{~mA}$ for 0.063 seconds and at a focus-totarget distance of $35 \mathrm{~cm}$ was used. Radiographic densities of the specimens, expressed as grayscale values (0 to 255), were measured with an accompanying software program (Trophy for Windows, Trophy Radiology) and converted into equivalent thicknesses of Al.

Three abutments and analogs for bone-level implants (Nobel Biocare) were selected for evaluation. The abutments were tightened with a torque wrench onto analogs, which were mounted in selfpolymerizing acrylic resin (Stigmall, ICN Galenika). The crown replicas were fabricated by using wax patterns. The castings were done in nickel-chromium alloy with a high-frequency induction casting machine. Porcelain (VK 95, Vita Zahnfabrik) was used for the buildup. Its application and condensation were standardized as much as possible within the confines of the usual laboratory techniques for fabricating metal-ceramic crowns with porcelain shoulders. Thereafter, the crowns were luted on the abutments with provisional cement (Temp Bond NE, 3M ESPE), which was carefully removed from the crown-abutment junction under $\times 10$ magnification to ensure that no marginal excess was present. In addition, three recently extracted human caries-free mandibular molars were collected to serve as controls; they were stored in $10 \%$ neutral buffered formalin solution until experimental procedures were initiated. Each tooth was fixed in a square mold so that the roots were embedded in acrylic resin up to $2 \mathrm{~mm}$ below the cementoenamel junction.

Samples of artificial interproximal cement excesses were made out of Al alloy 1100 (99.6\% purity) and four routinely used luting agents (Table 1). Stainless steel molds, $0.5 \mathrm{~mm}$ and $1 \mathrm{~mm}$ thick and with internal measurements of $3 \times 0.5 \mathrm{~mm}$, were used to create the cement specimens. They were then ground with $300-$ and 600-grit silicone carbide paper using an $\times 10$ magnifying scale loupe to create specimens with various thicknesses (mesiodistally), heights (occlusogingivally), and depths (buccolingually) (Table 1). It was impossible to create specimens that were 0.1 and $0.3 \mathrm{~mm}$ thick with Harvard zinc phosphate (Harvard Dental International) and with Ketac Cem Easymix (3M ESPE) because these materials displayed a high cracking rate. A digital caliper (Mitutoyo) was used to control the thicknesses, heights, and depths of the specimens to within $\pm 0.01 \mathrm{~mm}$.

The artificial cement excesses were attached to the abutments with colorless radiolucent glue at the middle of the interproximal surfaces (Fig 1) and the teeth on the cement just below the cementoenamel junction. Each implant restoration and tooth was radiographed with one of the prepared Al or cement artificial overhangs oriented with its thickness perpendicular to the axis of the radiographic source. The same digital sensor, $x$-ray unit, and exposure parameters described previously were used. In addition, the assembly was radiographed on occlusal dental film (Extraspeed, Insight Kodak) using an $\mathrm{x}$-ray unit (Gendex) operating at the same parameters as for the digital measurements, except for the exposure time. For the traditional radiographs, exposure times were determined by trial and error in an effort to produce images with similar levels of contrast to those obtained clinically. A 16-mm-thick block of modeling wax was positioned between the $x$-ray tube and the implant restoration/tooth to serve as a soft tissue analog. ${ }^{16}$

The digital radiographs were saved as regular .tiff and large .tiff files, which corresponded to low-resolution (LR) and high-resolution (HR) digital images, respectively. 


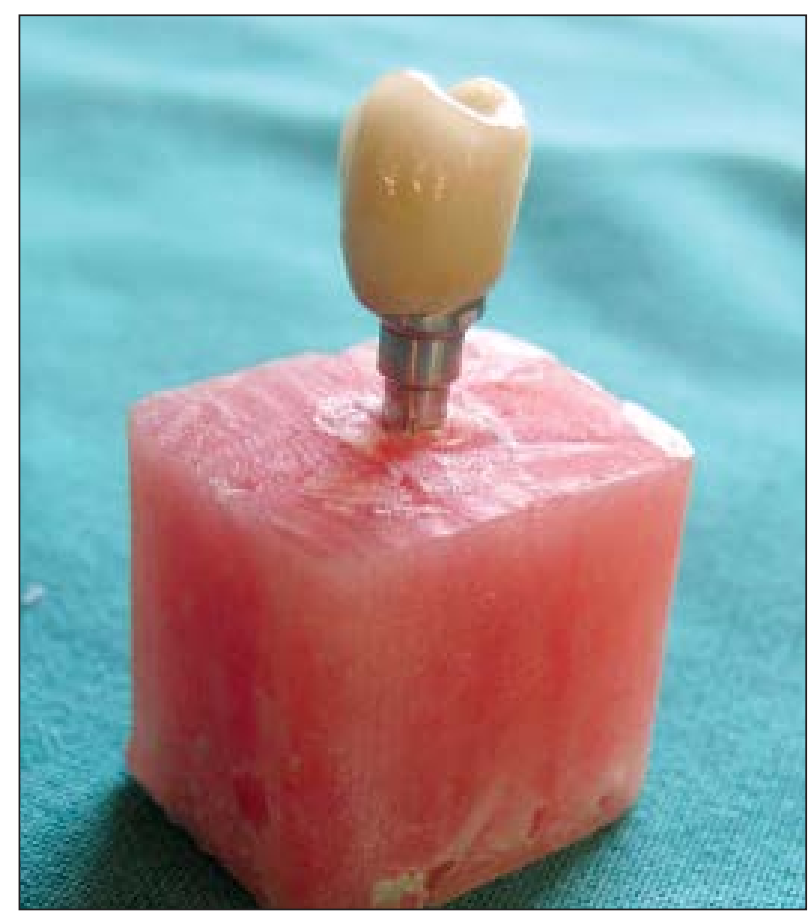

Fig 1 RelyX Unicem Automix artificial overhang (0.1 mm thick, $0.5 \mathrm{~mm}$ high, and $2 \mathrm{~mm}$ deep) attached to the interproximal side of the abutment.

\section{Table 1 Data on Tested Cements}

\begin{tabular}{|c|c|}
\hline Name & Type of material \\
\hline Harvard zinc phosphate cement & Zinc phosphate \\
\hline Ketac Cem Easymix & Glass ionomer \\
\hline Speed CEM & Composite \\
\hline RelyX Unicem Automix shade A2 & Composite \\
\hline Aluminum & Aluminum $(99.6 \% \mathrm{pu}$ \\
\hline
\end{tabular}

a,b,c Same superscript letters indicate no significant difference between cement radiopacity values $(P>.05)$.

Two-way ANOVA revealed that there was a significant difference in the minimum threshold for detection for the different cements $(P<.05)$ (Table 4 , Fig 2). There were also differences in the minimum radiopacity values needed for the visualization of cement overhangs with respect to the imaging system $(P<.05)$ (Table 4, Fig 3). The thickness of the specimens significantly influenced the detection threshold value $(P<.05)$ (Table 4, Fig 4), while height was not a significant factor in radiographic detection $(P>.05)$. The mean threshold value for the detection of cement overhangs was not significantly different for abutments versus tooth surfaces $(P>.05)$. Table 5 presents the results of the post hoc Tukey test for the factors material type, cement thickness, and imaging system $(P<.05)$.

\section{DISCUSSION}

ing contrast and brightness. The series of conventional and digital radiographs with the artificial cement excesses were shown to five trained evaluators, who were asked to identify the radiographs in which they could first detect the cement excess.

A two-way analysis of variance (ANOVA) comprising the factors imaging system, thickness of the specimens, and cement type was used. If a significant difference was detected, the post hoc Tukey test was used for comparisons between groups. An unpaired Student $t$ test was used to compare the data for the implant abutments with that for the teeth and to compare the data for different specimen heights. The level of significance was set at $P<.05$.

\section{RESULTS}

The radiopacity values of the tested cements are presented in Table 1. There were significant differences between the cements in terms of their radiopacity $(P<.05)$. Tables 2 and 3 depict the threshold radiopacity values for detection of the $\mathrm{Al}$ and cement specimens tested.
The results of the current study indicate that all cements exceed the minimum ISO specification of $1 \mathrm{~mm}$ Al. However, the findings of the present study contradict the proposed criteria for optimum radiopacity of dental cements. The results of this study stipulate that cement material should have a radiopacity of at least $1.7 \mathrm{~mm} \mathrm{Al}$ on HR digital radiographs and $2.1 \mathrm{~mm} \mathrm{Al}$ on LR digital radiographs to allow for visualization of a 0.1-mm-thick cement overhang adjacent to an implant abutment. When conventional radiography is used, radiopacity should be even greater $(2.2 \mathrm{~mm} \mathrm{Al})$.

The radiopacity of the Harvard zinc phosphate cement was $5.98 \mathrm{~mm} \mathrm{Al}$, which agrees reasonably well with previously published values for other zinc phosphate cements $\left(6 \mathrm{~mm} \mathrm{Al}^{17}\right.$ and $\left.6.4 \mathrm{~mm} \mathrm{Al}^{18}\right)$. The radiopacity of Ketac Cem (2.15 mm Al) corroborated the finding of Attar et $\mathrm{al}^{18}(1.9 \mathrm{~mm} \mathrm{Al})$ but is somewhat different from the findings of the study by Tsuge (5.1 mm Al). ${ }^{19}$ The radiopacity of RelyX Unicem was equivalent to $2.25 \mathrm{~mm} \mathrm{Al}$; previous studies cited values of $2.64 \mathrm{~mm} \mathrm{Al},{ }^{20} 3.54 \mathrm{~mm} \mathrm{Al},{ }^{21} 4 \mathrm{~mm} \mathrm{Al},{ }^{17}$ and 


\begin{tabular}{|c|c|c|c|c|}
\hline \multirow[b]{2}{*}{ Manufacturer } & \multirow{2}{*}{$\begin{array}{c}\text { Mean radiopacity } \\
\text { (mm Al/mm material) }\end{array}$} & \multicolumn{3}{|c|}{ Artificial cement excess (mm) } \\
\hline & & Height & Thickness & Depth \\
\hline Richter and Hoffmann & $5.98^{a}$ & $0.5,1$ & 0.5 & $0.5,1,1.5,2,2.5,3$ \\
\hline 3M ESPE & $2.15^{b}$ & $0.5,1$ & 0.5 & $0.5,1,1.5,2,2.5,3$ \\
\hline Ivoclar Vivadent & $4.15^{c}$ & $0.5,1$ & $0.1,0.3,0.5$ & $0.5,1,1.5,2,2.5,3$ \\
\hline 3M ESPE & $2.25^{\mathrm{b}}$ & $0.5,1$ & $0.1,0.3,0.5$ & $0.5,1,1.5,2,2.5,3$ \\
\hline Alprom & 1 & $0.5,1$ & $0.1,0.3,0.5$ & $0.5,1,1.5,2,2.5,3$ \\
\hline
\end{tabular}

\section{Table 2 Mean Radiopacity Threshold Values ( \pm Standard Deviations) for Detection of Artificial} Cement Overhangs in Association with Natural Teeth

$\begin{array}{lllcll}\text { Material } & \text { Height }(\mathrm{mm}) & \text { Thickness }(\mathrm{mm}) & \begin{array}{c}\text { Conventional } \\ \text { radiography }(\mathrm{mm} \text { Al) }\end{array} & \begin{array}{c}\text { HR digital } \\ \text { radiography }(\mathrm{mm} \text { Al) }\end{array} & \begin{array}{c}\text { LR digital } \\ \text { radiography }(\mathrm{mm} \text { Al) }\end{array}\end{array}$

Harvard zinc phosphate cement

$\begin{array}{lllll}0.5 & 0.5 & 0.5 \pm 0 & 0.5 \pm 0 & 0.5 \pm 0 \\ 1 & 0.5 & 0.5 \pm 0 & 0.5 \pm 0 & 0.5 \pm 0\end{array}$

Ketac Cem Easymix

$\begin{array}{lllll}0.5 & 0.5 & 0.7 \pm 0.2739 & 0.5 \pm 0 & 0.7 \pm 0.2739 \\ 1 & 0.5 & 0.6 \pm 0.2236 & 0.5 \pm 0 & 0.8 \pm 0.2739\end{array}$

RelyX Unicem Automix shade A2

\begin{tabular}{lllll}
0.5 & 0.1 & $2.4 \pm 0.2236$ & $0.9 \pm 0.2236$ & $1.1 \pm 0.2236$ \\
& 0.3 & $1.1 \pm 0.2236$ & $0.6 \pm 0.2236$ & $0.8 \pm 0.2739$ \\
& 0.5 & $1.2 \pm 0.2739$ & $0.5 \pm 0$ & $0.7 \pm 0.2739$ \\
\hline 1 & 0.1 & $2.3 \pm 0.2739$ & $0.9 \pm 0.2236$ & $0.8 \pm 0.2739$ \\
& 0.3 & $1.1 \pm 0.2236$ & $0.6 \pm 0.2236$ & $0.7 \pm 0.2739$ \\
& 0.5 & $1.2 \pm 0.2739$ & $0.5 \pm 0$ & $0.7 \pm 0.2739$
\end{tabular}

Speed CEM

$\begin{array}{lllll}0.5 & 0.1 & 0.9 \pm 0.2236 & 0.9 \pm 0.2236 & 0.9 \pm 0.2236 \\ & 0.3 & 0.5 \pm 0 & 0.5 \pm 0 & 0.5 \pm 0 \\ & 0.5 & 0.6 \pm 0.2236 & 0.5 \pm 0 & 0.5 \pm 0 \\ 1 & 0.1 & 0.9 \pm 0.2236 & 0.8 \pm 0.2739 & 0.9 \pm 0.2236 \\ & 0.3 & 0.6 \pm 0.2236 & 0.5 \pm 0 & 0.6 \pm 0.2236 \\ & 0.5 & 0.5 \pm 0 & 0.5 \pm 0 & 0.5 \pm 0\end{array}$

Aluminum

\begin{tabular}{lllll}
0.5 & 0.1 & $2.3 \pm 0.2738$ & $1.6 \pm 0.2236$ & $2.2 \pm 0.2739$ \\
& 0.3 & $0.7 \pm 0.2236$ & $0.8 \pm 0.2739$ & $1.2 \pm 0.2739$ \\
& 0.5 & $0.7 \pm 0.2236$ & $0.5 \pm 0$ & $1.2 \pm 0.2739$ \\
1 & 0.1 & $2.3 \pm 0.2738$ & $1.7 \pm 0.2739$ & $2.2 \pm 0.2739$ \\
& 0.3 & $0.7 \pm 0.2236$ & $0.8 \pm 0.2739$ & $0.7 \pm 0.2739$ \\
& 0.5 & $0.7 \pm 0.2236$ & $0.5 \pm 0$ & $1.4 \pm 0.2236$ \\
\hline
\end{tabular}

4.7 $\mathrm{mm} \mathrm{Al.}{ }^{19}$ There are no data in the literature for the radiopacity of Speed Cem. Differences between the present results and those of other studies presumably arise from factors such as the purity of the aluminum used, ${ }^{22}$ the methods used for evaluation, ${ }^{23}$ and the thickness of the specimens. ${ }^{19}$
In interpreting the findings of this study, a number of factors should be considered. First, the $\mathrm{ISO}^{24,25}$ does not declare the level of radiopacity that is required for different materials; that is to say, a material that has been reported as radiopaque according to ISO standards may be insufficiently radiopaque for clinical conditions. 


\section{Table 3 Mean Radiopacity Threshold Values ( \pm Standard Deviations) for Detection of Artificial} Cement Overhangs in Association with Implant Abutments

Conventional

HR digital

LR digital

Material

Height (mm)

Thickness (mm)

radiography (mm Al)

radiography $(\mathrm{mm} \mathrm{Al})$ radiography $(\mathrm{mm} \mathrm{Al})$

Harvard zinc phosphate cement

$\begin{array}{lllll}0.5 & 0.5 & 0.5 \pm 0 & 0.5 \pm 0 & 0.5 \pm 0 \\ 1 & 0.5 & 0.5 \pm 0 & 0.5 \pm 0 & 0.5 \pm 0\end{array}$

Ketac Cem Easymix

$\begin{array}{lllll}0.5 & 0.5 & 0.7 \pm 0.2739 & 0.5 \pm 0 & 0.7 \pm 0.2739 \\ 1 & 0.5 & 0.7 \pm 0.2739 & 0.5 \pm 0 & 0.7 \pm 0.2739\end{array}$

RelyX Unicem Automix shade A2

0.5

$\begin{array}{ll}0.1 & 2.2 \pm 0.2739 \\ 0.3 & 0.7 \pm 0.2739 \\ 0.5 & 0.5 \pm 0 \\ 0.1 & 2.1 \pm 0.2236 \\ 0.3 & 0.7 \pm 0.2739 \\ 0.5 & 0.5 \pm 0\end{array}$

$0.8 \pm 0.2739$

$0.8 \pm 0.2739$

10.5

1$$
0.5
$$

$\begin{array}{ll}0.5 & 0.1 \\ & 0.3 \\ & 0.5 \\ 1 & 0.1 \\ & 0.3 \\ & 0.5\end{array}$

$\begin{array}{ll}0.1 & 1.1 \pm 0.2236 \\ 0.3 & 0.6 \pm 0.2236 \\ 0.5 & 0.5 \pm 0 \\ 0.1 & 0.9 \pm 0.2236 \\ 0.3 & 0.5 \pm 0 \\ 0.5 & 0.5 \pm 0\end{array}$

$0.5 \pm 0$

$0.6 \pm 0.2236$

$0.5 \pm 0$

$0.5 \pm 0$

Speed CEM

Aluminum

\begin{tabular}{lllll}
0.5 & 0.1 & $2.2 \pm 0.2739$ & $1.7 \pm 0.2739$ & $2.1 \pm 0.2236$ \\
& 0.3 & $0.7 \pm 0.2739$ & $0.6 \pm 0.2236$ & $0.6 \pm 0.2236$ \\
1 & 0.5 & $0.7 \pm 0.2739$ & $0.5 \pm 0$ & $0.5 \pm 0$ \\
& 0.1 & $2.2 \pm 0.2739$ & $1.7 \pm 0.2739$ & $2.1 \pm 0.2739$ \\
& 0.3 & $0.7 \pm 0.2739$ & $0.6 \pm 0.2236$ & $0.6 \pm 0.2236$ \\
& 0.5 & $0.7 \pm 0.2739$ & $0.5 \pm 0$ & $0.5 \pm 0$ \\
\hline
\end{tabular}

\begin{tabular}{|c|c|c|c|c|c|}
\hline Source & $\begin{array}{l}\text { Type III sum of } \\
\text { squares }\end{array}$ & df & Mean square & $\mathbf{F}$ & $P$ value \\
\hline Corrected model & 175.917 & 131 & 1.343 & 34.757 & .000 \\
\hline Intercept & 398.356 & 1 & 398.356 & 10310.396 & .000 \\
\hline Material type & 27.892 & 4 & 6.973 & 180.478 & .000 \\
\hline Thickness & 65.093 & 2 & 32.546 & 842.375 & .000 \\
\hline Imaging system & 8.950 & 2 & 4.475 & 115.817 & .000 \\
\hline Material type $\times$ thickness & 22.710 & 4 & 5.678 & 146.948 & .000 \\
\hline Material type $\times$ imaging system & 11.066 & 8 & 1.383 & 35.803 & .000 \\
\hline Thickness $\times$ imaging system & 9.132 & 4 & 2.283 & 59.092 & .000 \\
\hline Error & 20.400 & 528 & 0.039 & & \\
\hline Total & 636.500 & 660 & & & \\
\hline Corrected total & 196.317 & 659 & & & \\
\hline
\end{tabular}

1072 Volume 28, Number 4, 2013

(c) 2013 BY QUINTESSENCE PUBLISHING CO, INC. PRINTING OF THIS DOCUMENT IS RESTRICTED TO PERSONAL USE ONLY. NO PART MAY BE REPRODUCED OR TRANSMITTED IN ANY FORM WITHOUT WRITTEN PERMISSION FROM THE PUBLISHER. 

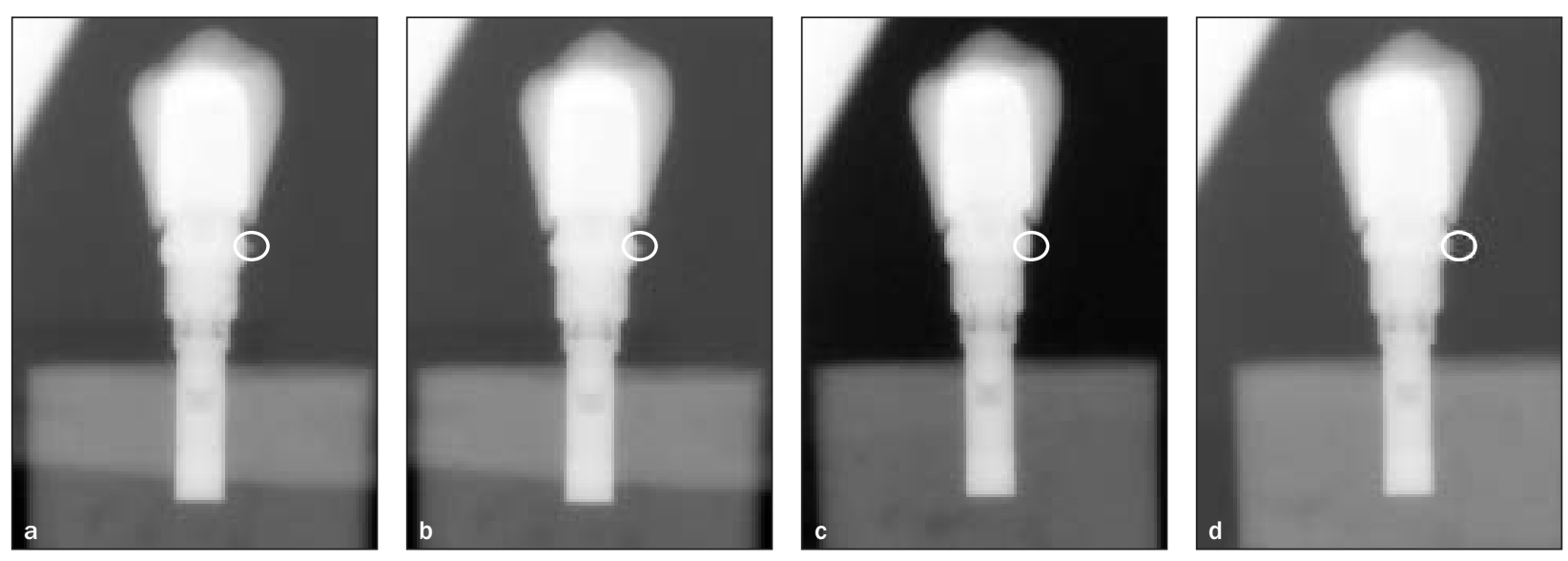

Fig 2 HR digital images of (a) Harvard zinc phosphate and (b) Ketac Cem Easymix artificial cement overhangs (0.5 mm thick, $0.5 \mathrm{~mm}$ high, and $0.5 \mathrm{~mm}$ deep) attached to the interproximal side of the abutment and (c) RelyX Unicem Automix and (d) Speed Cem artificial overhangs $(0.1 \mathrm{~mm}$ thick, $0.5 \mathrm{~mm}$ high, and $0.5 \mathrm{~mm}$ deep) attached to the interproximal side of the abutment. Note that the RelyX Unicem Automix cement overhang is not visible on the radiograph.

Fig 3 (a) HR digital image and (b) conventional image of Al artificial overhangs $(0.1 \mathrm{~mm}$ thick, $0.5 \mathrm{~mm}$ high, and $2 \mathrm{~mm}$ deep) attached to the right interproximal side of the implant abutment and $0.3 \mathrm{~mm}$ thick on the left side of the implant abutment on conventional film. Note that the 0.1-mm-thick overhang is not visible on the conventional radiograph, while it is visible on the HR digital radiograph.

Fig 4 HR digital images of aluminum artificial overhangs that are $0.5 \mathrm{~mm}$ high, $1 \mathrm{~mm}$ deep, and (a) $0.1 \mathrm{~mm}$, (b) $0.3 \mathrm{~mm}$, and (c) $0.5 \mathrm{~mm}$ thick attached to the interproximal side of the implant abutment.
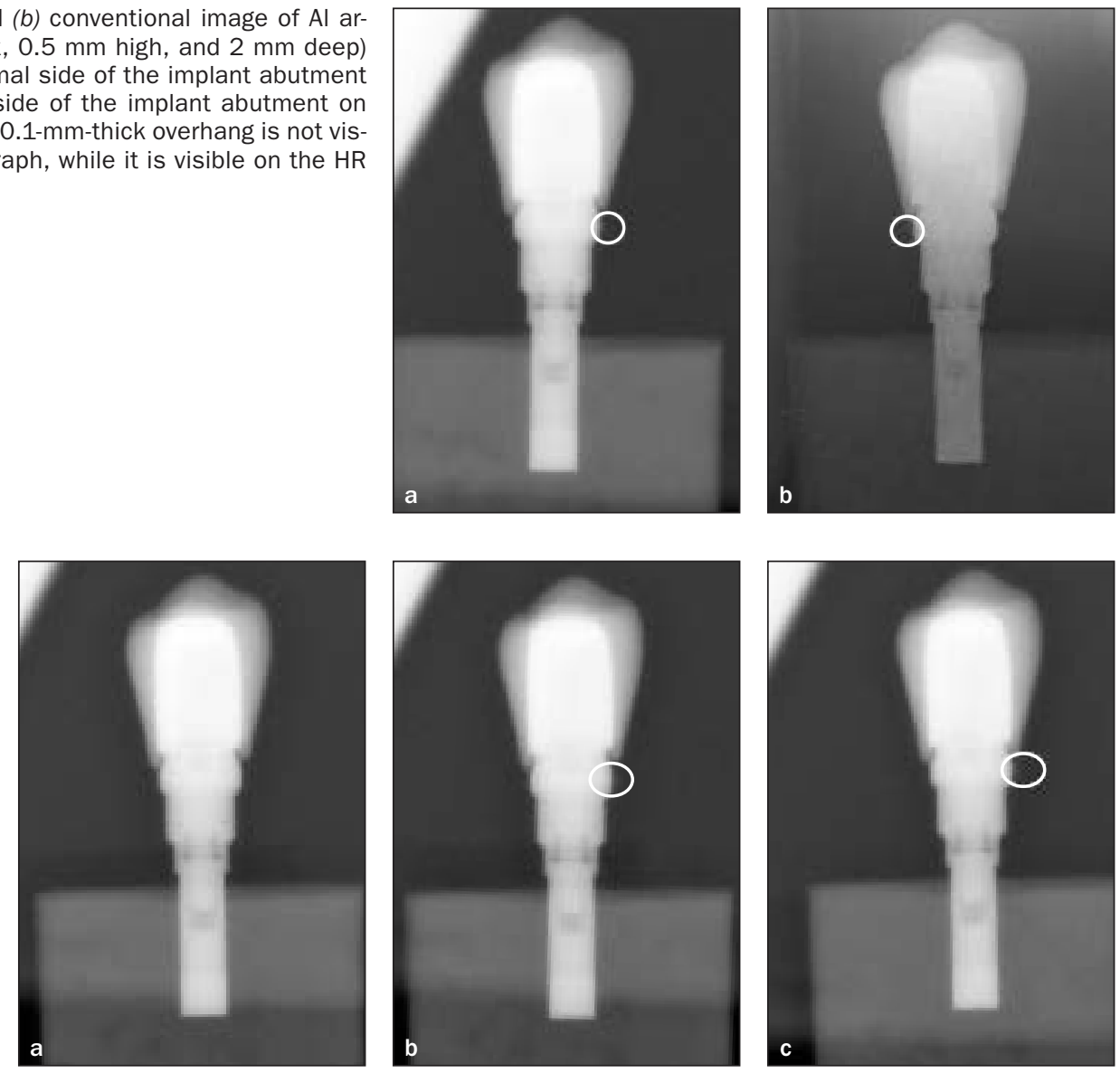

For instance, the proposed radiopacity of $1 \mathrm{~mm}$ Al was not sufficient to allow for detection of a $0.1-\mathrm{mm}$-thick cement overhang, either on a natural tooth or attached to the abutment surface. Second, for traditional restorations, sufficient radiopacity is essential for two reasons: to make it possible to distinguish between the material

and recurrent caries ${ }^{26}$ and to allow detection of cement overhangs in subgingival areas. ${ }^{16}$ Because excessive radiopacity can obscure caries adjacent to a restoration, materials with a moderate degree of radiopacity are preferable to those with a high degree of radiopacity. ${ }^{27}$ In implant dental prostheses, metal abutments do not 


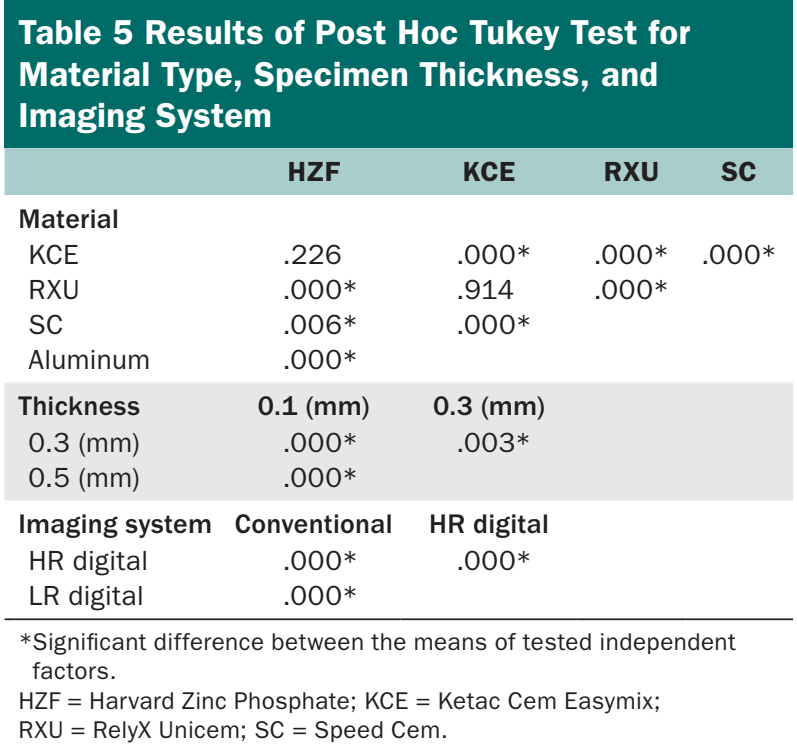

decay, and as such, they are not at risk of this complication. On the other hand, residual cement is one of the main factors associated with peri-implant disease, which is not an issue with tooth-supported restorations. This implies that, in cemented implant prostheses, luting agents with the highest possible level of radiopacity should be used. Third, there is a consensus in the literature that material should be more radiopaque than surrounding structures so that it can be visualized on radiographs. ${ }^{28}$ Although there is no data on the radiopacity of titanium abutments, the radiopacity values of titanium dental posts and titanium alloys are reported to be equivalent to $5.12 \mathrm{~mm} \mathrm{Al}$ and $6.93 \mathrm{~mm} \mathrm{Al}$, respectively. ${ }^{29,30}$ If these values are accurate, cement materials attached to an implant surface should have a radiopacity value of at least $5 \mathrm{~mm}$ Al. However, the results of this study show that radiopacity values no higher than $1.7 \mathrm{~mm} \mathrm{Al}$ on HR digital radiographs and $2.2 \mathrm{~mm} \mathrm{Al}$ on conventional radiographs were sufficient for cement identification adjacent to abutment surfaces.

The results of this study stipulate that the thickness of the cement excess influences the threshold of detectable radiopacity. A cement excess of $0.5 \mathrm{~mm}$ in thickness adjacent to an abutment should be as radiopaque as $0.5 \mathrm{~mm} \mathrm{Al}$ on HR digital radiographs, and a 0.1 -mm-thick cement specimen should have a radiopacity of at least $1.7 \mathrm{~mm}$ Al. The threshold radiopacity value of cement excess is influenced, in addition, by two factors related to the surrounding structures: an edge enhancement phenomenon and the contours of surrounding structures. An edge enhancement phenomenon allows highly radiopaque materials to mask surrounding structures that are not very radiopaque and/or are thin. For instance, a cement overhang is more difficult to detect adjacent to a composite inlay than when it is placed in conjunction with a radiolucent porcelain inlay. ${ }^{16}$ Masking of small cement increments can especially be expected adjacent to yttria-stabilized and ceria-stabilized zirconia ceramic systems, which are reported to be as radiopaque as $26.8 \mathrm{~mm} \mathrm{Al}$ and $22.9 \mathrm{~mm} \mathrm{Al}$, respectively. ${ }^{31} \mathrm{On}$ the other hand, the contour of a restoration determines the tangential thickness of the cement (the cement layer that is visible when viewed tangentially on the side of abutments). ${ }^{21}$ Therefore, when a thinner layer of the cement overhang is present on the interproximal surface, the chance of overlooking it during radiographic examination is greater. However, in the present study, there were no significant differences in the threshold radiopacity value for cement excesses in association with abutments and natural teeth.

Digital radiographic analysis offers a better chance of detection of cement remnants owing to the greater sensitivity of the digital sensor when compared with film and the manipulation of the images, including adjustments of resolution, magnification, and contrast. $^{32}$ The resolution of an LR .tiff image taken with the Trophy RVG sensor was 37 pixels, whereas the HR .tiff format digital radiographs had a resolution of 96 pixels, which allowed smaller cement overhangs to be detected. This leads to the conclusion that, in patients with suspected cement remnants on implant restorations, digital radiography should be used and images saved at the highest possible resolution. In addition, it may be surmised that adjusting the magnification and contrast on digital radiographs may lead to easier identification of cement overhangs. Further studies are needed to verify this hypothesis.

Esthetic paradigms require that crown margins be left subgingivally; a position 1 to $2 \mathrm{~mm}$ subgingival has been recommended as a reference point for many clinicians. ${ }^{33}$ One may argue that radiographic detection of cement overhangs may be accomplished only for cement excesses placed interproximally and that facial and lingual surfaces are not available for radiographic evaluation. However, the depth of the implant margin is approximately two times greater interproximally, in comparison to the facial and lingual regions, because most abutments do not follow the contour of the cementoenamel junction. Thus, a sulcus depth of $1.5 \mathrm{~mm}$ on the facial and lingual surfaces can increase to $3 \mathrm{~mm}$ on the interproximal surfaces..$^{13}$ Linkevicius et $\mathrm{al}^{34}$ advocated that removal of cement excesses will not be successful around implant restorations with subgingival margins positioned $2 \mathrm{~mm}$ or deeper. Thus, it is thought that removal of residual cement on facial and lingual surfaces is not a major concern for clinicians. Moreover, most abutments, such as those used in this study, have a lingual cementation margin that 
is located supragingivally to allow clinicians to clean off excess cement without difficulties. It is generally agreed that the depth of the margin plays the crucial role in the successful removal of cement remnants. Radiography allows the visualization of cement excess on the interproximal side of the abutment, where the depth of the sulcus is the greatest and thus, from the clinical point of view, the most critical area to keep clear of excess cement.

\section{CONCLUSION}

The most important finding of this experiment is that excess cement around implant restorations may be detected with high probability by digital radiographic procedures. The minimum radiopacity value necessary for the detection of thin layers of cement overhangs is higher than that recommended by International Organization for Standardization directives. Therefore, clinicians are encouraged to use highly radiopaque dental cements and to take follow-up digital images after deep subgingival restorations are luted to detect any cement remnants on interproximal implant or abutment surfaces. Further research is warranted to determine whether the results of the current study would be replicated in clinical situations.

\section{ACKNOWLEDGMENT}

The authors reported no conflicts of interest related to this study.

\section{REFERENCES}

1. Hebel KS, Gajjar RC. Cement-retained versus screw-retained implant restorations: Achieving optimal occlusion and esthetics in implant dentistry. J Prosthet Dent 1997;77:28-35.

2. Chiche GJ, Pinault A. Considerations for fabrication of implantsupported posterior restorations. Int J Prosthodont 1991;4:37-44.

3. Keith SE, Miller BH, Woody RD, Higginbottom FL. Marginal discrepancy of screw-retained and cemented metal-ceramic crowns on implants abutments. Int J Oral Maxillofac Implants 1999;14:369-378.

4. Weber HP, Kim DM, Ng MW, Hwang JW, Fiorellini JP. Peri-implant soft-tissue health surrounding cement- and screw-retained implant restorations: A multi-center, 3-year prospective study. Clin Oral Implants Res 2006;17:375-379.

5. Jemt T, Lekholm U, Grondahl K. A 3-year followup study of early single implant restorations ad modum Brånemark. Int J Periodontics Restorative Dent 1990;10:340-349.

6. Jung RE, Pjetursson BE, Glauser R, Zembic A, Zwahlen M, Lang NP. A systematic review of the 5 -year survival and complication rates of implant-supported single crowns. Clin Oral Implants Res 2008;19: 119-130.

7. Pauletto N, Lahiffe BJ, Walton JN. Complications associated with excess cement around crowns on osseointegrated implants: A clinical report. Int J Oral Maxillofac Implants 1999;14:865-868.

8. Wilson TG. The positive relationship between excess cement and peri-implant disease: A prospective clinical endoscopic study. J Periodontol 2009;80:1388-1392.
9. Albrektsson T, Isidor F. Consensus report: Implant therapy. In: Lang NP, Karring T (eds). Proceedings of the First European Workshop on Periodontology. Berlin: Quintessence, 1994:365-369.

10. Zitzmann NU, Berglundh T. Definition and prevalence of periimplant diseases. J Clin Periodontol 2008;35:286-291.

11. Charalampakis G, Rabe P, Leonhardt A, Dahlen G. A follow-up study of peri-implantitis cases after treatment. J Clin Periodontol 2011;38:864-871.

12. Lang NP, Berglundh T, Heitz-Mayfield LJ, Pjetursson BE, Salvi GE, Sanz M. Consensus statements and recommended clinical procedures regarding implant survival and complications. Int J Oral Maxillofac Implants 2004;19:150-154.

13. Agar JR, Cameron SM, Hughbanks JC, Parker MH. Cement removal from restorations luted to titanium abutments with simulated subgingival margins. J Prosthet Dent 1997;78:43-47.

14. Claffey N, Clarke E, Polyzois I, Renvert S. Surgical treatment of periimplantitis. J Clin Periodontol 2008;35:316-332.

15. Wadhwani C, Rapoport D, La Rosa S, Hess T, Kretschmar S. Radiographic detection and characteristic patterns of residual excess cement associated with cement-retained implant restorations: A clinical report. J Prosthet Dent 2012;107:151-157.

16. O'Rourke B, Walls AW, Wassell RW. Radiographic detection of overhangs formed by resin composite luting agents. J Dent 1995;23: 353-357.

17. Fonseca RB, Branco CA, Soares PV, et al. Radiodensity of base, liner and luting dental materials. Clin Oral Investig 2006;10:114-118.

18. Attar N, Tam LE, McComb D. Mechanical and physical properties of contemporary dental luting agents. J Prosthet Dent 2003;89:127-134.

19. Tsuge TJ. Radiopacity of conventional, resin-modified glass ionomer, and resin-based luting materials. Oral Sci 2009;51:223-230.

20. Gu S, Rasimick BJ, Deutsch AS, Musikant BL. Radiopacity of dental materials using a digital X-ray system. Dent Mater 2006;22:765-770.

21. Wadhwani C, Hess T, Faber T, Piñeyro A, Chen CS. A descriptive study of the radiographic density of implant restorative cements. J Prosthet Dent 2010;103:295-302.

22. Watts DC, McCabe JF. Aluminium radiopacity standards for dentistry: An international survey. J Dent 1999;27:73-78.

23. Baksi BG, Sen BH, Eyuboglu TF. Differences in aluminum equivalent values of endodontic sealers: Conventional versus digital radiography. J Endod 2008;34:1101-1104

24. International Organization for Standardization. ISO 9917:1998. Dentistry: Water-based Cements. Geneva, Switzerland.

25. International Organization for Standardization. ISO 4049:2009. Dentistry: Polymer-based Restorative Materials. Geneva, Switzerland.

26. Rubo MH, el-Mowafy O. Radiopacity of dual-cured and chemicalcured resin-based cements. Int J Prosthodont 1998;11:70-74.

27. Espelid I, Tveit AB. Diagnosis of secondary caries and crevices adjacent to amalgam. Int Dent J 1991;41:359-364.

28. Nomoto R, Mishima A, Kobayashi K, et al. Quantitative determination of radio-opacity: Equivalence of digital and film X-ray systems. Dent Mater 2008;24:141-147.

29. Finger WJ, Ahlstrand WM, Fritz UB. Radiopacity of fiber-reinforced resin posts. Am J Dent 2002;15:81-84.

30. Pekkan G, Pekkan K, Hatipoglu MG, Tuna SH. Comparative radiopacity of ceramics and metals with human and bovine dental tissues. J Prosthet Dent 2011;106:109-117.

31. Okuda Y, Noda M, Kono H, Miyamoto M, Sato H, Ban S. Radio-opacity of core materials for all-ceramic restorations. Dent Mater J 2010;29:35-40.

32. Patel S, Dawood A, Whaites ET, Ford P. New dimensions in endodontic imaging: Part 1. Conventional and alternative radiographic systems. Int Endod J 2009;42:447-462.

33. Belser UC, Buser D, Hess D, Schmid B, Bernard JP, Lang NP. Aesthetic implant restorations in partially edentulous patients-A critical appraisal. Periodontol 2000 1998;17:132-150.

34. Linkevicius T, Vindasiute E, Puisys A, Peciuliene V. The influence of margin location on the amount of undetected cement excess after delivery of cement-retained implant restorations. Clin Oral Implants Res 2011;22:1379-1384. 